\title{
ADAPTAÇÃO DO MÉTODO CONTÍNUO DE SECAGEM PARA SEMENTES DE ARROZ
}

\author{
Walter Araujo Motta'; Francisco Amaral Villela ${ }^{1,2 *}$; Gilberto Jaime Zimmer \\ ${ }^{1}$ Universidade Federal de Pelotas, C.P. 354 - CEP: 96010-900 - Pelotas, RS. \\ ${ }^{2}$ Bolsista do CNPq. \\ *e-mail: bloisvillela@uol.com.br
}

RESUMO: Com o objetivo de avaliar a influência da adaptação do método contínuo de secagem sobre a qualidade das sementes de arroz durante o armazenamento, quatro porções de sementes, pesando cada uma $2500 \mathrm{~kg}$, foram secadas em secador de fluxo contínuo Kepler Weber, modelo KW-2, utilizando diferentes temperaturas do ar, respectivamente, nas câmaras de secagem, superior e inferior: $60 / 40^{\circ} \mathrm{C}$; $60 / 50^{\circ} \mathrm{C} ; 70 / 50^{\circ} \mathrm{C} ; 70 / 60^{\circ} \mathrm{C}$ e um tratamento testemunha, constituído por quatro amostras submetidas à secagem estacionária em estufa regulada à temperatura constante de $32^{\circ} \mathrm{C}$. A qualidade das sementes foi avaliada através dos seguintes testes: grau de umidade, germinação, envelhecimento artificial e emergência em campo, conduzidos em quatro épocas, correspondentes aos 0, 60, 120 e 180 dias de armazenamento em condições ambientais não controladas. Os componentes do beneficiamento industrial foram determinados na primeira época de avaliação. Os resultados obtidos permitiram concluir que lotes de sementes de arroz com alta porcentagem de grãos quebrados podem apresentar elevada qualidade fisiológica; na secagem contínua adaptada, as sementes de arroz podem ser submetidas a temperaturas do ar de até $60^{\circ} \mathrm{C}$ e $50^{\circ} \mathrm{C}$, respectivamente, nas câmaras superior e inferior, apesar de causar redução acentuada na porcentagem de grãos inteiros.

Palavras-chave: Oryza sativa, secagem, semente, qualidade, armazenamento

\section{ADAPTATION OF THE CONTINUOUS DRYING METHOD FOR RICE SEEDS}

ABSTRACT: To evaluate the effects of the adaptation of the continuous drying method on seed quality during storage, four portions of rice seeds of $2500 \mathrm{~kg}$ each, were dried, in a continuous flow dryer $\mathrm{KW}$ 2 Kepler Weber, using different temperatures in the upper and lower drying chambers: $60 / 40^{\circ} \mathrm{C} ; 60 / 50^{\circ} \mathrm{C}$; $70 / 50^{\circ} \mathrm{C} ; 70 / 60^{\circ} \mathrm{C}$. As control, four samples were submitted to stationary drying in oven at $32^{\circ} \mathrm{C}$. Seed quality was evaluated through moisture content, germination, accelerated aging and field emergence tests, at the $\mathbf{0 , 6 0 , 1 2 0}$ and 180 days of storage, at room temperature. The industrial processing components were determined in the first evaluation. Rice seed lots with high percentage of broken grains can present high physiological quality. Maximum air temperatures of $60^{\circ} \mathrm{C}$ and $50^{\circ} \mathrm{C}$ at the upper and lower chambers could be used in continuous drying of rice seeds. The adapted continuous drying decreases the percentage of intact grains of rice.

Key words: Oryza sativa, drying, seed, quality, storage

\section{INTRODUÇÃO}

Da produção nacional de arroz, mais de $70 \%$ é proveniente de lavouras irrigadas. 0 Estado do Rio Grande do Sul contribui com 45\% desse total, ocupando uma área aproximada de 800 mil hectares. Isto mostra a necessidade de produzir grandes quantidades de sementes, utilizando tecnologias que priorizem a obtenção de altos níveis de qualidade a baixo custo, como exige a atual conjuntura econômica nacional. Para tanto, há necessidade do desenvolvimento de tecnologias que permitam corrigir as distorções técnico-científicas existentes no setor produtivo, sobremaneira nas áreas de secagem e armazenamento.

Sementes de arroz provenientes de lavouras irrigadas são colhidas com altos teores de água e em condições ambientais de umidade relativa e temperaturas elevadas (Villela \& Peske, 1996), tornando a secagem artificial operação indispensável, que, em geral, constituise num ponto de estrangulamento na unidade de beneficiamento de sementes (UBS).

$\mathrm{Na}$ secagem de sementes de arroz irrigado, normalmente, utiliza-se o método intermitente, por meio de secadores intermitentes ou contínuos, sendo que estes apresentam, no 
mínimo, duas câmaras, uma de secagem e outra de resfriamento, e são adaptados para operar dessa forma. Além disso, uma das câmaras de secagem é utilizada como câmara de equalização. Nesse método é indicado uma temperatura do ar que atravessa a câmara de secagem, em geral, não superior a $70^{\circ} \mathrm{C}$.

$A$ adoção de um sistema de secagem contínua, com fluxo de ar aquecido através das duas câmaras do secador e passagem das sementes diversas vezes pelo conjunto secadorelevador, poderá constituir-se numa opção capaz de reduzir custos operacionais, pela possibilidade de diminuir o tempo de secagem e a energia consumida.

De modo geral, os secadores contínuos não são recomendados na secagem de sementes, porém admite-se essa possibilidade desde que se proceda determinadas modificações, tais como, o aumento do número de passagens e da velocidade de fluxo da massa de sementes através da câmara de secagem (Aguirre \& Peske, 1992). Estas modificações tornam-se necessárias visto que na secagem contínua, a manutenção de temperaturas e fluxos de ar elevados promovem rápida remoção da água das sementes e, como conseqüência, pode provocar a fissura das sementes (Kunze, 1979) e afetar negativamente a qualidade fisiológica das sementes, particularmente durante o período de armazenamento (Villela \& Peske, 1996).

A fissura não é uma ruptura superficial, mas resulta de uma expansão da superfície, devido a sorção de água do ar ambiente, do interior da semente ou de ambos. As células da superfície da semente ao sofrerem expansão, exercem uma compressão, enquanto as células da região interna sofrem contração e desenvolvem uma tração sobre a porção interna, a partir de um gradiente de pressão decrescente na semente, após um período de secagem rápida, ocasionando as fissuras. O fissuramento não ocorre no final da secagem, mas algum tempo após, porque os grãos parcialmente secos apresentam um gradiente de umidade, sendo necessário um certo período para anular a diferença de potencial hídrico. A medida que ocorre a transferência de água, o gradiente de potencial hídrico decresce, durante o período que transcorre entre o término da secagem e o início do fissuramento que continua até que o gradiente de umidade na semente torne-se nulo. O gradiente de umidade na semente parece ser o fator principal que causa o fissuramento e, portanto, em função das condições do ar de secagem, podem resultar diferentes gradientes de umidade (Kunze, 1979).

Secando sementes de arroz com teores iniciais de água de 19,0 e $20,8 \%$ em secador intermitente e utilizando temperaturas do ar de $60,70,80$ e $90^{\circ} \mathrm{C}$, Rosa (1966) verificou que as temperaturas de 80 e $90^{\circ} \mathrm{C}$ causaram reduções acentuadas na germinação imediatamente após a secagem e que as temperaturas de 60 e $70^{\circ} \mathrm{C}$ não produziram efeitos imediatos e latentes sobre as sementes. Observou, ainda, que a temperatura da massa de sementes atingiu $42,2^{\circ} \mathrm{C}$, com o ar de secagem aquecido a $70^{\circ} \mathrm{C}$, o que sugere a utilização desta temperatura sem prejudicar a qualidade fisiológica do arroz. Esses resultados foram confirmados por Luz \& Peske (1988) que, ao secarem sementes de arroz em secador intermitente, utilizando temperatura do ar de secagem de $70^{\circ} \mathrm{C}$ e variando o fluxo de ar, a umidade inicial das sementes e o tempo de exposição ao ar aquecido, não observaram reduções significativas na germinação e no vigor das sementes.

A adequação do sistema contínuo à secagem de sementes de arroz deve estar embasada no conhecimento da influência que poderá representar a ação continuada de temperaturas elevadas do ar de secagem sobre a qualidade fisiológica de sementes e sobre o rendimento de grãos inteiros. Esta última informação tem em vista, principalmente, a utilização pela agroindústria de lotes de sementes descartados na UBS ou do excedente de produção de sementes.

O objetivo do presente trabalho foi avaliar a influência da adaptação do método contínuo de secagem sobre a qualidade das sementes de arroz durante o armazenamento.

\section{MATERIAL E MÉTODOS}

O trabalho foi conduzido na Unidade de Beneficiamento de Sementes (UBS), no Laboratório Didático de Análise de Sementes (LDAS) e no Campo Didático do Departamento de Fitotecnia, da Faculdade de Agronomia Eliseu Maciel, da Universidade Federal de Pelotas.

Foram utilizadas 10 toneladas de sementes de arroz (Oryza sativa L.), do cultivar BR-IRGA 410, provenientes de um campo de produção de semente fiscalizada, do município de Arroio Grande, RS, produzidas na safra 95/96.

As sementes foram recebidas na UBS com grau de umidade, expresso em base úmida, de $21 \%$. Quatro amostras, pesando cada uma 
$5 \mathrm{~kg}$, sofreram secagem estacionária, em estufa regulada à temperatura constante de $32^{\circ} \mathrm{C}$, até o teor de água de $13 \%$, constituindo a testemunha (Test).

Quatro porções de sementes, cada uma pesando $2500 \mathrm{~kg}$, foram secadas em secador de fluxo contínuo marca Kepler Weber, modelo $\mathrm{KW}-2$, com capacidade estática de $2.500 \mathrm{~kg}$, sendo $1400 \mathrm{~kg}$ na câmara superior, $1000 \mathrm{~kg}$ na câmara inferior e $100 \mathrm{~kg}$ no elevador. O sistema permite a secagem com injeção de ar aquecido nas duas câmaras e foi regulado para realizar a descarga em 30 minutos. A utilização de diferentes tempe-raturas do ar de secagem constituiu os demais tratamentos, conforme descrito na TABELA 1.

TABELA 1 - Temperaturas do ar de secagem e das sementes de arroz utilizadas na secagem contínua.

\begin{tabular}{lcccc}
\hline & \multicolumn{3}{c}{ Temperatura $\left({ }^{\circ} \mathrm{C}\right)$ na camâra } \\
\cline { 2 - 5 } & \multicolumn{2}{c}{ Superior } & \multicolumn{2}{c}{ Inferior } \\
\cline { 2 - 5 } Tratamento & Ar & Semente* & Ar & Semente $^{*}$ \\
$60 / 40$ & 60 & 36 & 40 & 32 \\
$60 / 50$ & 60 & 38 & 50 & 34 \\
$70 / 50$ & 70 & 36 & 50 & 30 \\
$70 / 60$ & 70 & 42 & 60 & 36 \\
\hline
\end{tabular}

* Temperatura máxima.

Ao final de cada secagem foram retiradas quatro amostras de sementes, pesando cada uma $5 \mathrm{~kg}$, sendo a primeira coletada 10 minutos após o início da operação de descarga do secador, e as outras três, mantendo intervalo de 5 minutos entre a coleta de cada uma. Cada amostra foi dividida em quatro frações de mesmo peso que, a seguir, foram acondicionadas em sacos de algodão e mantidas em condições não controladas de ambiente (temperatura variável de 10 a $26^{\circ} \mathrm{C}$ e umidade relativa de 70 a $95 \%$ ), em uma sala do LDAS, por um período de seis meses. O período de armazenamento que se estendeu de abril a outubro de 1996, foi dividido em quatro épocas de avaliação, correspondentes aos 0, 60, 120 e 180 dias de armazenamento.

Em cada época, após a coleta das amostras para avaliação da qualidade das sementes, uma fração de cada amostra foi acondicionada em saco de papel e mantida em câmara seca e fria, à temperatura de $15^{\circ} \mathrm{C}$ e umidade relativa de $50 \%$, até outubro, época de condução do teste de emergência em campo.
Para avaliação da qualidade das sementes foram utilizadas as seguintes determinações:

Grau de umidade - realizada pelo método da estufa a $105^{\circ} \mathrm{C} \pm 3^{\circ} \mathrm{C}$, por 24 horas, e o resultado expresso em base úmida, conforme as Regras para Análise de Sementes (Brasil, 1992).

Teste de germinação - foram utilizadas quatro repetições de cinqüenta sementes, em rolo de papel toalha umedecido com uma quantidade de água igual a 2,5 vezes o peso do papel seco. O germinador foi regulado à temperatura constante de $25^{\circ} \mathrm{C}$, as avaliações efetuadas no sétimo e no décimo quatro dia após a semeadura e os resultados expressos em porcentagem de plântulas normais.

Teste de envelhecimento artificial conduzido com quatro repetições de cinqüenta sementes, utilizando o método da caixa gerbox, contendo $40 \mathrm{ml}$ de água destilada, conforme metodologia descrita por Marcos Filho et al. (1987). As caixas contendo as sementes foram mantidas em estufa à temperatura de $42^{\circ} \mathrm{C}$, durante $96 \mathrm{~h}$. A seguir, foi conduzido o teste de germinação, com avaliação no sétimo dia após a semeadura e os resultados expressos em porcentagem de plântulas normais.

Emergência em campo - quatro repetições de cinqüenta sementes foram semeadas no espaçamento entre as linhas de $10 \mathrm{~cm}$, utilizando, nas linhas, cinqüenta sementes por metro linear. Procedeu-se à contagem do número de plântulas emersas no décimo quarto dia após a semeadura e os resultados foram expressos em porcentagem.

Componentes do beneficiamento industrial - quatro amostras de $100 \mathrm{~g}$ de sementes foram descascadas e polidas em um engenho de provas marca Suzuki. Os grãos inteiros e os quebrados foram separados por meio de um trieur de provas marca Kepler Weber. O peso da casca foi determinado pela diferença entre os pesos da amostra e de grãos descascados; o de farelo pela diferença entre os pesos de grãos descascados e de grãos polidos. Os pesos de grãos inteiros e de quebrados foram obtidos, após a separação no trieur, diretamente por pesagem. Os resultados foram expressos em porcentagem de cada um desses componentes em relação ao peso da respectiva amostra.

O delineamento experimental utilizado foi inteiramente ao acaso, com quatro repetições, dentro de cada época de avaliação. As médias foram comparadas pelo teste de Tukey ao nível de $5 \%$ de probabilidade. 
A análise da variância dos dados de componentes do beneficiamento industrial foi em delineamento inteiramente ao acaso com quatro repetições, na primeira época de avaliação, e as médias comparadas pelo teste de Tukey ao nível de $5 \%$ de probabilidade.

Antes das análises, os dados de germinação, envelhecimento artificial e emergência em campo sofreram a transformação arco seno da raíz quadrada da \%/100. Para facilitar a interpretação dos parâmetros avaliados, os resultados foram apresentados por meio de médias dos dados originais.

\section{RESULTADOS E DISCUSSÃO}

Os dados referentes ao beneficiamento industrial de arroz (TABELA 2) mostram para todos os tratamentos, com exceção do 70/60, semelhança quanto ao rendimento de descascamento e ao percentual de farelo. Os grãos polidos (inteiros + quebrados) representaram $66,6 \%$ do peso total da amostra no tratamento da secagem contínua que utilizou $70^{\circ} \mathrm{C}$ na câmara superior e $60^{\circ} \mathrm{C}$ na câmara inferior e $67,8 \pm 0,1 \%$ nos demais tratamentos. Esses percentuais estão de acordo com os 62 a $70 \%$ obtidos por Büttow \& Bilhalva (1979) para 10 cultivares de arroz submetidas ao beneficiamento industrial com umidades entre 12,4 e $13,8 \%$.

Apenas no tratamento testemunha o rendimento de grãos inteiros ficou dentro da faixa de 47 a $60 \%$, encontrada por Büttow \& Bilhalva (1979). A porcentagem de grãos quebrados representa, provavelmente, aquela provocada pelas condições ambientais no campo.

$\mathrm{Na}$ secagem contínua os percentuais de grãos inteiros foram significativamente menores em relação à secagem estacionária.
A temperatura da massa de sementes tende a aumentar nos estádios finais do processo de secagem quando a quantidade de água a ser evaporada torna-se menor, elevando os gradientes térmico e hídrico entre a superfície e o interior da semente, tornando-a mais suscetível ao fissuramento e, em conseqüência, a determinar maior porcentagem de quebra no beneficiamento, de acordo com Villela \& Peske (1996). Este fato foi observado por Zimmer et al. (1992) que, ao secarem sementes de arroz pelo sistema de seca-aeração, transferindo as sementes do secador intermitente para os silos aerados com umidade de 15 a $16 \%$, obtiveram rendimentos de grãos inteiros superiores aos verificados na secagem intermitente até a umidade final de $13 \%$.

Os resultados obtidos na secagem contínua mostram que, embora a temperatura da massa de sementes não ultrapasse $36^{\circ} \mathrm{C}$ (tratamentos 60/40 e 70/50), expõe as sementes durante períodos de tempo dilatados a temperaturas elevadas do ar, tendo em vista a permanência das sementes em contato com o ar aquecido nas duas câmaras do secador. Em conseqüência, ocorre uma rápida secagem superficial da semente, formando acentuados gradientes de umidade entre as partes internas e a superfície da semente que podem promover sua ruptura. Esta constatação vem confirmar que, na secagem contínua, a manutenção de temperaturas e fluxos de ar elevados promovem rápida retirada de água, o que segundo Kunze (1979) pode provocar o trincamento da semente. Apesar dos resultados obtidos, vale destacar a importância que assume a manutenção de alta porcentagem de grãos inteiros na produção de sementes de arroz, tendo em vista o excedente de sementes e o descarte de lotes de baixa qualidade destinados à industrialização para consumo.

TABELA 2 - Componentes do beneficiamento industrial convencional de arroz sob diferentes tratamentos de secagem.

\begin{tabular}{lcccc}
\hline \multirow{2}{*}{ Tratamentos } & \multicolumn{4}{c}{ Porcentagem sobre o peso da amostra } \\
\cline { 2 - 5 } & Casca & Farelo & Grãos & Quebrados \\
\hline Test & $21,5 \mathrm{a}$ & $10,8 \mathrm{a}$ & $57,8 \mathrm{a}$ & $9,9 \mathrm{a}$ \\
$60 / 40$ & $21,1 \mathrm{a}$ & $11,0 \mathrm{a}$ & $43,8 \mathrm{~b}$ & $24,1 \mathrm{c}$ \\
$60 / 50$ & $21,3 \mathrm{a}$ & $10,9 \mathrm{a}$ & $38,2 \mathrm{c}$ & $29,6 \mathrm{~d}$ \\
$70 / 50$ & $21,2 \mathrm{a}$ & $11,0 \mathrm{a}$ & $45,3 \mathrm{~b}$ & $22,5 \mathrm{~b}$ \\
$70 / 60$ & $23,0 \mathrm{~b}$ & $10,4 \mathrm{~b}$ & $28,5 \mathrm{~d}$ & $38,1 \mathrm{e}$
\end{tabular}

Médias seguidas por uma mesma letra, nas colunas, não diferem entre si pelo teste de Tukey $(\alpha=0,05)$. 
$\mathrm{Na}$ TABELA 3 observa-se que, no início do armazenamento, o teor de água das sementes diferiu entre os tratamentos, com o tratamento 70/ 60 apresentando o menor grau de umidade $(11,8 \%)$ e o tratamento $70 / 50$, o maior $(14,9 \%)$. Aos 60 dias de armazenamento as diferenças entre os tratamentos tornaram-se menores e, aos 120 dias, elas não diferiram. Porém, 180 dias após o início do armazenamento, as diferenças voltaram a ser observadas tendo, em números absolutos, os tratamentos 70/50 e 60/50 apresentado os maiores teores de água (13,7\% e $13,6 \%$ ) e os tratamentos $70 / 60$ e $60 / 40$, os menores $(13,1 \%)$.

O tratamento 70/50, devido ao elevado teor de água inicial, continuou secando durante todo o período de armazenamento. Nos demais tratamentos, nota-se um aumento do grau de umidade até 120 dias e, a partir daí, uma redução, ocorrência esta verificada, também, por Rodriguez (1988) e Rangel et al. (1997), em sementes de arroz, armazenadas em condições ambientais de Pelotas, RS.

Verifica-se na TABELA 3 que em cada época de avaliação, a menor porcentagem de germinação foi observada no tratamento 70/60, embora não tenha diferido do tratamento 60/50 imediatamente após a secagem, da testemunha aos 60 dias e dos tratamentos 60/40 e 70/50 aos 120 dias. Os demais tratamentos não diferiram entre si até os 60 dias de armazenamento e, aos 180 dias, o tratamento 70/50 também apresentou germinação inferior à da testemunha.

Ao longo do período de armazenamento constata-se, de maneira geral, redução da germinação e, ao final de 180 dias de armazenamento, os percentuais de germinação foram superiores a $80 \%$, somente para os tratamentos testemunha e 60/40.

A redução mais acentuada na germinação das sementes submetidas à secagem contínua pode ser em razão da prolongada exposição a temperaturas do ar de secagem elevadas, conforme Prasad \& Chandra (1994) e Villela \& Peske (1996). Por outro lado, excetuando-se os tratamentos da secagem contínua que utilizaram $70^{\circ} \mathrm{C}$ na câmara superior de secagem, as reduções no poder germinativo das sementes após 180 dias de armazenagem foram similares às verificadas por Rodriguez

TABELA 3 - Valores médios (\%) obtidos do grau de umidade e do teste de germinação conforme os tratamentos de secagem dentro de cada época de avaliação.

\begin{tabular}{|c|c|c|c|c|}
\hline \multicolumn{5}{|c|}{ Grau de Umidade } \\
\hline \multirow{2}{*}{ Tratamentos } & \multicolumn{4}{|c|}{ Épocas (dias) } \\
\hline & 0 & 60 & 120 & 180 \\
\hline Test & $12,5 c$ & $14,0 a b$ & $14,7 \mathrm{a}$ & $13,3 a b$ \\
\hline $60 / 40$ & $13,4 b$ & $13,7 \mathrm{~b}$ & $14,6 \mathrm{a}$ & $13,1 \mathrm{~b}$ \\
\hline $60 / 50$ & $12,8 \mathrm{c}$ & $13,8 a b$ & $14,3 \mathrm{a}$ & $13,6 \mathrm{a}$ \\
\hline $70 / 50$ & 14,9 a & $14,3 \mathrm{a}$ & $14,6 \mathrm{a}$ & $13,7 \mathrm{a}$ \\
\hline $70 / 60$ & $11,8 d$ & $13,6 \mathrm{~b}$ & $14,4 \mathrm{a}$ & $13,1 \mathrm{~b}$ \\
\hline \multicolumn{5}{|l|}{ CV(\%): 0,586 } \\
\hline \multicolumn{5}{|c|}{ Teste de Germinação } \\
\hline \multirow{2}{*}{ Tratamentos } & \multicolumn{4}{|c|}{ Épocas (dias) } \\
\hline & 0 & 60 & 120 & 180 \\
\hline Test & $91 \mathrm{a}$ & $85 a b$ & $90 \mathrm{a}$ & $85 \mathrm{a}$ \\
\hline $60 / 40$ & $90 \mathrm{a}$ & 89 a & $82 \mathrm{bc}$ & $83 a$ \\
\hline $60 / 50$ & $88 a b$ & $87 \mathrm{a}$ & $83 \mathrm{~b}$ & $79 a b$ \\
\hline $70 / 50$ & $90 \mathrm{a}$ & $90 \mathrm{a}$ & $81 \mathrm{bc}$ & $76 \mathrm{~b}$ \\
\hline $70 / 60$ & $84 \mathrm{~b}$ & $81 \mathrm{~b}$ & $76 \mathrm{c}$ & $67 c$ \\
\hline
\end{tabular}

$\mathrm{CV}(\%): 2,332$

Médias seguidas por uma mesma letra, na coluna, não diferem entre si pelo teste de Tukey $(\alpha=0,05)$. 
(1988), ao armazenar sementes de arroz secadas pelo método da seca-aeração.

O vigor das sementes, avaliado pelo teste de envelhecimento artificial (TABELA 4) mostrou, nas quatro épocas de avaliação, a inferioridade do tratamento 70/60 em relação aos demais e a superioridade dos tratamentos testemunha e 60/40 comparativamente ao tratamento 70/50.

Ao longo do período de armazenamento observa-se uma diminuição no vigor das sementes, em todos os tratamentos, a partir de sessenta dias de armazenamento.

Apesar dos problemas de metodologia apontados por Tekrony (1995), que podem interferir nos resultados, constata-se que a separação de médias indicada no teste de envelhecimento artificial foi a mesma verificada para o teste de germinação após 180 dias de armazenamento, o que vem mostrar sua eficiência em estimar o potencial de armazenamento, concordando com os resultados alcançados por Delouche \& Baskin (1973).

A TABELA 4 mostra que, em todas as épocas o tratamento 70/60 apresentou menor porcentagem de emergência em campo, apesar de não diferir dos tratamentos 70/50 e testemunha aos 60 dias. Os demais tratamentos não diferiram, salvo aos 180 dias de armazenamento quando as sementes provenientes dos tratamentos 60/40, 60/50 e 70/ 50 apresentaram o melhor desempenho, embora os dois primeiros não tenham diferido da testemunha.

Numa análise global, é possível constatar que houve uma redução na emergência de plântulas, ao longo do período de armazenamento, nos tratamentos testemunha e $70 / 60$, conforme também constatado por Rodriguez (1988), caracterizando uma diminuição no vigor das sementes. Vale destacar que, de acordo com Carvalho (1994), este teste pode fornecer uma boa previsão da potencialidade de um lote, quando conduzido na época recomendada para a semeadura da espécie.

Os resultados obtidos no teste de emergência em campo mostram os efeitos prejudiciais causados pelo tratamento 70/60, o que foi verificado, também, nos testes de germinação e envelhecimento artificial. Por outro

TABELA 4 - Valores médios (\%) obtidos do teste de envelhecimento artificial e do teste de emergência em campo conforme os tratamentos de secagem dentro de cada época de avaliação.

\begin{tabular}{|c|c|c|c|c|c|}
\hline \multicolumn{6}{|c|}{ Teste de Envelhecimento Artificial } \\
\hline \multirow{2}{*}{ Tratamentos } & \multicolumn{4}{|c|}{ Épocas (dias) } & \multirow[b]{2}{*}{ Médias } \\
\hline & 0 & 60 & 120 & 180 & \\
\hline Test & 88 & 93 & 82 & 85 & $97 \mathrm{a}$ \\
\hline $60 / 40$ & 91 & 91 & 81 & 83 & $86 a$ \\
\hline $60 / 50$ & 85 & 88 & 81 & 79 & $83 a b$ \\
\hline $70 / 50$ & 80 & 88 & 80 & 77 & $81 \mathrm{~b}$ \\
\hline $70 / 60$ & 75 & 79 & 65 & 66 & $71 \mathrm{c}$ \\
\hline \multicolumn{6}{|l|}{ CV(\%): 3,323} \\
\hline \multicolumn{6}{|c|}{ Teste de Emergência em Campo } \\
\hline \multirow{2}{*}{ Tratamentos } & \multicolumn{4}{|c|}{ Épocas (dias) } & \\
\hline & 0 & 60 & 120 & 180 & \\
\hline Test & $91 \mathrm{a}$ & $86 a b$ & $85 \mathrm{a}$ & $84 \mathrm{~b}$ & \\
\hline $60 / 40$ & 89 a & $91 \mathrm{a}$ & $87 \mathrm{a}$ & $90 a b$ & \\
\hline $60 / 50$ & $88 \mathrm{a}$ & $88 \mathrm{a}$ & $87 \mathrm{a}$ & $88 a b$ & \\
\hline $70 / 50$ & $88 \mathrm{a}$ & $86 \mathrm{a}$ & $83 a$ & $91 \mathrm{a}$ & \\
\hline $70 / 60$ & $78 \mathrm{~b}$ & $78 \mathrm{~b}$ & $73 \mathrm{~b}$ & $72 c$ & \\
\hline
\end{tabular}

CV(\%): 3,194

Médias seguidas por uma mesma letra, na coluna, não diferem entre si pelo teste de Tukey $(\alpha=0,05)$. 
lado, diferenças mais sutis entre os demais tratamentos, detectadas no teste de envelhecimento artificial não foram observadas no teste de emergência em campo, provavelmente, porque as condições ambientais foram favoráveis na época de condução do referido teste.

Não obstante terem sido verificadas diferenças pronunciadas entre os tratamentos de secagem quanto às porcentagens de grãos inteiros e de quebrados (TABELA 2), as mesmas não ocorreram no teste de germinação (TABELA 3 ), envelhecimento artificial e emergência em campo (TABELA 4), evidenciando que lotes de sementes de arroz que apresentam altas porcentagens de grãos quebrados, não exibem, necessariamente, baixa qualidade fisiológica. Este fenômeno se deve, de acordo com Luz \& Peske (1988), ao fato de que as reservas embrionárias são suficientes para produzir uma plântula normal ou a fissura não representa uma barreira ao transporte de reservas do endosperma.

Outra hipótese que se pode levantar é que a porção remanescente do endosperma que permanece ligada ao embrião, após a ruptura, possa conter uma quantidade de reservas capaz de garantir o processo de germinação.

\section{CONCLUSÕES}

- Lotes de sementes de arroz com altas porcentagens de grãos quebrados podem apresentar elevada qualidade fisiológica;

- Na secagem contínua adaptada, as sementes de arroz podem ser submetidas a temperaturas de até $60^{\circ} \mathrm{C}$ na câmara superior e $50^{\circ} \mathrm{C}$ na câmara inferior, apesar de a qualidade da semente não ser afetada, ocorre uma redução acentuada na porcentagem de grãos inteiros.

\section{REFERÊNCIAS BIBLIOGRÁFICAS}

AGUIRRE, R.; PESKE, S.T. Manual para el beneficio de semillas. Cali: Centro Internacional de Agricultura Tropical, 1992. 247p.

BRASIL. Ministério da Agricultura e Reforma Agrária. Secretaria Nacional de Defesa Agropecuária. Regras para análise de sementes. Brasília, 1992. 365p.

BÜTTOW, J.; BILHALVA, A.B. Rendimento de engenho e avaliações químicas das variedades do ensaio regional do arroz (Oryza sativa, L.) 1978/79. In: REUNIÃO DA CULTURA DO ARROZ IRRIGADO, 9., Pelotas, 1979. Anais. Porto Alegre: IRGA, 1979. p.185-187.
CARVALHO, N.M. O conceito de vigor em sementes. In: VIEIRA, R.D.; CARVALHO, N.M. Testes de vigor em sementes. Jaboticabal: FUNEP, 1994. p.1-25.

DELOUCHE, J.C.; BASKIN, C.C. Accelerated aging techniques for predicting the relative storability of seed lots. Seed Science and Technology, v.1, n.2, p.427-452, 1973.

KUNZE, O.R. Fissuring of the rice grain after heated air drying. Transactions of the ASAE, v.22, n.5, p.1197-1207, 1979.

LUZ, C.A.S.; PESKE, S.T. Secagem de sementes de arroz em secador intermitente lento. Revista Brasileira de Sementes, v.10, n.2, p.103-114, 1988.

MARCOS FILHO, J.; CICERO, S.M.; SILVA, W.R. Avaliação da qualidade das sementes. Piracicaba: FEALQ, 1987. 230p.

PRASAD, B.V.; CHANDRA, P.K. Drying parboiled rough rice in stationary semi-fluidized and fluidized. Transactions of the ASAE, v.37, n.2, p.589-601, 1994.

RANGEL, M.A.S.; ZIMMER, G.J.; VILLELA, F.A. Secagem estacionária de sementes de arroz com ar ambiente. Pesquisa Agropecuária Brasileira, v.32, n.10, p.1081-1090, 1997.

RODRIGUEZ, G. G. Efeitos da seca-aeração no armazenamento de sementes de arroz em condições ambientais. Pelotas, 1988. 55p. Dissertação (Mestrado) - Faculdade de Agronomia Eliseu Maciel, Universidade Federal de Pelotas.

ROSA, O.S. Temperaturas recomendadas para a secagem de sementes de trigo e arroz utilizando o método intermitente. In: SEMINÁRIO PANAMERICANO DE SEMILLAS, 5., Macaray, 1966. Anais. Macaray, 1966. 27p.

TEKRONY, D.M. Accelerated aging. In: INTERNATIONAL SEED TESTING ASSOCIATION. Seed vigour testing seminar. Copenhagen: Vigour Test Committee, 1995. p.56-72.

VILLELA, F.A.; PESKE, S.T. Secagem e beneficiamento de sementes de arroz irrigado. In: PESKE, S.T.; NEDEL, J.L.; BARROS, A.C.S.A. Produção de arroz. Pelotas: UFPel, 1996. p.435-473.

ZIMMER, G.J.; VILLELA, F.A.; TILLMANN, M.A.A.; ZONTA, E.P. Seca-aeração para sementes de arroz. Pesquisa Agropecuária Brasileira, v.27, n.9, p.1371-1378, 1992

Recebido para publicação em 11.12 .98

Aceito para publicação em 10.08.99 